\title{
Early-onset drinking in Ireland: negative outcomes and behaviours.
}

\section{AUTHOR(S)}

Theodore D. Cosco, Karen Morgan, Laura Currie, Hannah McGee

\section{CITATION}

Cosco, Theodore D.; Morgan, Karen; Currie, Laura; McGee, Hannah (2013): Early-onset drinking in Ireland: negative outcomes and behaviours.. Royal College of Surgeons in Ireland. Journal contribution. https://hdl.handle.net/10779/rcsi.10772933.v1

\section{HANDLE}

10779/rcsi.10772933.v1

\section{LICENCE}

CC BY-NC-ND 4.0

This work is made available under the above open licence by RCSI and has been printed from https://repository.rcsi.com. For more information please contact repository@rcsi.com

\section{URL}

https://repository.rcsi.com/articles/journal_contribution/Earlyonset_drinking_in_Ireland_negative_outcomes_and_behaviours_/10772933/1 
Title: Early onset drinking in Ireland: Negative outcomes and behaviours Authors: Theodore D Cosco ${ }^{1}$, Karen Morgan ${ }^{23}$, Laura Currie ${ }^{2}$ Hannah McGee Affiliations: ${ }^{1}$ Cambridge Institute of Public Health, Department of Public Health and Primary Care, University of Cambridge; ${ }^{2}$ Department of Psychology, Division of Population Health Sciences, Royal College of Surgeons in Ireland; ${ }^{3}$ School of Medicine, PU-RCSI

Corresponding Author: Theodore D. Cosco; Cambridge Institute of Public Health, University of Cambridge, Forvie Site, Robinson Way, Cambridge, CB2 0SR; tdc33@medschl.cam.ac.uk; 07414983921

Funding: No funding was sought or acquired for the current study. 
The harmful effects of alcohol misuse are well documented, causing an estimated 1.8 million deaths worldwide annually [1]. Identifying the predictors of future alcohol misuse is an integral component in the prevention of these negative outcomes. The age at which one first consumes alcohol has been shown to be a predictor of future alcohol misuse; consuming alcohol at an early age has been linked with a 2-3 fold increase in the risk of developing alcohol abuse and alcohol dependence issues in later life [2]. Early onset drinking has also been linked with significantly higher rates of self-injury [3], drinking and driving $[4,5]$, missing work/school, getting into trouble at work/school, and getting lower grades at school [5] as a result of one's drinking, as well as having longterm impact on neurocognitive functioning [6]. A sharp decline in risk for future alcohol abuse and dependence behaviours has been revealed in individuals who first consumed alcohol after the age of 14 [2]. These results suggest that individuals who first consume alcohol in early adolescence are at a significantly higher risk than individuals who postpone their drinking behaviours.

The age at onset of drinking alcohol in Ireland has steadily decreased over the past 70 years [7]. According to a recent Irish survey, the average age at which individuals first consume an entire alcoholic beverage, i.e. not a sip or taste, is between 13 and 14 years [8]. Furthermore, alcohol consumption in Ireland increased from 7.72 litres of pure alcohol per person in 1972 to 14.34 litres/person in 2002, despite decreasing levels of alcohol consumption in the rest of the European Union over this period [9]. The significance and pervasiveness 
of early onset alcohol use and misuse is thus a pressing issue, particularly in Ireland.

Given the increasing rates of alcohol consumption and decreasing age at first consumption in Ireland it is important to examine the negative effects these behaviours are having later in life. To this end, the current study cross-sectionally investigates the relationship between early onset drinking and a host of negative outcomes and attitudes across gender, marital status and education in a national sample of young adults in Ireland.

Procedure and Participants

Respondents to the 2007 national survey of lifestyle, attitudes and nutrition (SLÁN) aged 20 - 40 from the Republic of Ireland were followed-up in $2009(n=1039 ;$ response rate $82 \%)$ to complete a telephone interview regarding alcohol use and associated behaviours. SLÁN employed a multistage probability sample selected using a listing of residential addresses (further details available in Morgan, et al. [10]). The current study examines only the data collected during the 2009 follow-up study. The sample excluded individuals who responded that they had never consumed alcohol $(n=93 ; 1.1 \%)$.

Respondents were questioned about their alcohol consumption and whether or not they had experienced, in the past year, various negative outcomes associated with their own and others' alcohol consumption. Participants ranging in age from 20-40 were chosen from the overall adult sample of over 10,000 adults in order to investigate contemporary patterns of alcohol consumption for young adults. [8] 


\section{Variable Definitions}

Given the sharp decline in risk for future alcohol abuse and dependence behaviours in individuals who first consumed alcohol after age 14 years [2], 'early onset drinkers' (EODs) were defined as drinkers who reported consuming an entire alcoholic beverage, i.e. not just sips or tastes, on or before age 14. Age at first alcoholic drink was captured in the survey with the following question: "At what age did you start drinking?". This is the definition traditionally used in studies of early onset alcohol use [3].

\section{Data Analyses}

Data were analysed with STATA 11.0. The relationship between early onset drinking and negative outcomes was examined via binary logistic regression, adjusting for age and gender, across a number of demographic variables (gender, education, marital status). For each of the negative outcomes (in each of the demographic sub-groups) a separate binary logistic regression was conducted, using early onset drinking as the explanatory variable and the presence or absence of a negative outcome as the outcome variable, whilst adjustingfor age and gender.

\section{Demographic profile}

The sample of drinkers $(n=946)$ consisted of primarily women $(61.0 \%)$, ranging in age from 20 to 40 (mean 31.7 years). Forty-four percent were married and $37 \%$ were single. Education levels were high; $60 \%$ had completed some third level qualification. Regarding alcohol use, $4 \%$ had first consumed an entire 
alcoholic beverage on or below age 14. The average age of drinking onset was 18.1 years (SD 2.5; median: 18).

Early Onset Drinking and Negative Outcomes

EOD was significantly associated with an increased risk of feeling like you should cut down [OR 2.1 (1.0-4.2)] and having financial problems due to their own drinking [OR 6.9 (2.3-20.5)]. Male EODs were much more likely to be in an accident [OR 11.5 (2.2-59.9)], while female EODs were much more likely to report financial problems due to one's drinking [OR 12.7 (2.7-59.3)], than late onset drinkers. There were no negative outcomes associated with EODs for those with primary level education as their highest level of schooling; however, five outcomes were associated with EODs who had completed secondary education and three with those having completed third level education. EODs were not significantly associated with an increase in risk of negative outcomes based on marital status.

One negative outcome ("Being sexually assaulted") was not reported by any of the respondents and was, therefore, not included in the analysis.

\section{TABLE 1 ABOUT HERE}

The current study provides evidence of the association between early onset drinking and future negative outcomes. EODs were more likely to have suffered a negative outcome due to alcohol than respondents who first consumed alcohol after age 14. The association of early onset drinking with negative outcomes is consistent with previous findings; however, the current 
study revealed fewer significant relationships, but a greater effect, than similar studies, e.g. Rothman, et al. [5].

The average age of drinking onset in the current study was higher than previous Irish studies[8]. Palmer, et al [8], use the standard definition, i.e. age at first drink (AFD), in a survey of Irish 15 to 19 year olds, reporting an AFD of 13.4, nearly half a decade before the average AFD in the current study (18.4 years, median: 18). Given the greater range of ages in the current study, and the length of time that had elapsed since respondent AFD, issues with recall may have been a factor in this discrepancy.

Limitations in the current study are due to the relative rarity of individuals in the sample demonstrating EOD, possible selection bias, and the interpretation of the question "At what age did you start drinking?" A consequence of the low numbers of EODs is limited statistical power, manifesting in the inability to reach statistical significance. The sample had high levels of females and educated individuals respond to the survey, indicating the possibility of selection bias. Lower education levels have been associated with alcohol-related harm; however, in the current study sub-tertiary educated respondents were not associated with negative alcohol-related outcomes. This may have been due to the small sample of sub-tertiary-level educated respondents. Although the EOD identifying question has been used in previous studies, e.g. [3], the age at which one considers themselves to have started drinking can be misinterpreted or incorrectly recalled and is, therefore, another limitation. 
The current study provides evidence for an association between early onset of alcohol consumption and future negative outcomes. Respondents who consumed alcohol on or before age 14 were up to 7 times more likely to experience a negative alcohol-related outcome than respondents who first consumed alcohol after age 14. These results are of particular importance to populations, such as Ireland's, where the age at first drink is decreasing [6] and rates of alcohol consumption are increasing [8], highlighting the need for intervention. While a relationship between negative outcomes and early onset alcohol consumption has been identified, the underlying causes for this association are yet to be determined and, therefore, require further investigation. 


\section{Acknowledgements:}

The authors would like to thank to the SLAN 2007 follow-up study data collection team, Mary Conry, Yvonne McGowan, Ciana Maher and Helen Burke from RCSI.

L Currie was funded by the Health Research Board of Ireland through the PhD

Scholars Programme in Health Services Research under Grant no. PhD/2007/16.

Ethics approval for the SLAN study was granted by the Research Ethics

Committee of the Royal College of Surgeons in Ireland (RCSI).

Conflicts of Interest: None declared. 


\section{References}

1. World Health Organization, Global Status Report on Alcohol 2004, 2004, Department of Mental Health and Substance Abuse: Geneva.

2. DeWit, D.J., Adlaf, E.M., Offord, D.R. and Ogborne, A.C. , Age at first alcohol use: a risk factor for the development of alcohol disorders. Am J Psychiatry, 2000. 157(5): p. 745-50.

3. Hingson, R.W., Edwards, E.M., Heeren, T. and Rosenbloom, D., Age of Drinking Onset and Injuries, Motor Vehicle Crashes, and Physical Fights After Drinking and When Not Drinking. Alcoholism: Clinical and Experimental Research, 2009. 33(5): p. 783-790.

4. Hingson, R. and Winter, M., Epidemiology and consequences of drinking and driving. Alcohol Res Health, 2003. 27(1): p. 63-78.

5. Rothman, E.F., Dejong, W., Palfai, T. and Saitz, R., Relationship of Age of First Drink to Alcohol-Related Consequences Among College Students with Unhealthy Alcohol Use. Substance Abuse, 2008. 29(1): p. 33 - 41.

6. Squeglia, L.M., Pulido, C., Wetherill, R.R., Jacobus, J., Brown., G.G., and Tapert, S.F., Brain response to working memory over three years of adolescence: influence of initiating heavy drinking. J Stud Alcohol Drugs, 2012. 73(5): p. 749-60.

7. Smyth, B.P., Kelly, A. and Cox, G., Decline in Age of Drinking Onset in Ireland, Gender and Per Capita Alcohol Consumption. Alcohol Alcohol, 2011. 
8. Palmer, D. and O'Reilly, G., Young people, alcohol and drugs, 2008:

Dublin.

9. Department of Health and Children, Strategic task force on alcohol, Second Report, 2004: Dublin.

10. Morgan, K., McGee, H., Watson, D., Perry, I., Barry, M. and Shelley, E., SLAN 2007: Survey of Lifestyles, Attitudes, \& Nutrition in Ireland, 2008:

Dublin. 
Table 1: Relationships between early onset drinking and experiencing negative outcomes in the past year, by demographics: Odds ratios

\begin{tabular}{|c|c|c|c|c|c|c|c|c|c|c|c|}
\hline \multirow{3}{*}{$\begin{array}{l}\text { Item } \\
\text { Got into a fight }\end{array}$} & \multicolumn{2}{|r|}{ Total } & \multicolumn{4}{|c|}{ Gender } & \multicolumn{5}{|c|}{ Highest Education Completed } \\
\hline & & & & Men & & Women & Primary & & condary & & Tertiary \\
\hline & & - & & - & & - & - & 35.0 & $(3.3-371.9)$ & & - \\
\hline Been in an accident & & - & 11.5 & $(2.2-59.9)$ & & $\mathrm{n} / \mathrm{a}$ & $\mathrm{n} / \mathrm{a}$ & 10.8 & $(1.4-82.6)$ & & - \\
\hline Felt you should cut down & 2.1 & $(1.0-4.2)^{\star}$ & & - & & - & - & & - & & - \\
\hline Regretted something you said & & - & & - & & - & - & & - & & - \\
\hline Felt friendship or social life harmed & & - & & - & & - & $\mathrm{n} / \mathrm{a}$ & & - & 4.0 & $(1.4-11.6)$ \\
\hline Felt home life or marriage harmed & & - & & - & & $\mathrm{n} / \mathrm{a}$ & $\mathrm{n} / \mathrm{a}$ & & - & & - \\
\hline Felt work or studies harmed & & - & & - & & - & $\mathrm{n} / \mathrm{a}$ & & - & & - \\
\hline Felt health harmed & & - & & - & & - & - & & - & & - \\
\hline Felt effects of alcohol at work/college & & - & & - & & - & - & & - & & - \\
\hline Missed days of work/college & & - & & - & & - & $\mathrm{n} / \mathrm{a}$ & & - & & - \\
\hline $\begin{array}{l}\text { Had financial problems due to your } \\
\text { own drinking }\end{array}$ & 6.9 & $(2.3-20.5)^{\star}$ & & - & 12.7 & $(2.7-59.3)$ & $\mathrm{n} / \mathrm{a}$ & 13.2 & $(1.6-111.5)$ & 8.3 & $(2.0-33.9)$ \\
\hline Had property vandalized & & - & & - & & - & $\mathrm{n} / \mathrm{a}$ & & - & 2.6 & $(1.0-6.6)$ \\
\hline Been verbally abused & & - & & - & & - & - & & $\mathrm{n} / \mathrm{a}$ & & - \\
\hline
\end{tabular}


Been assaulted by someone drunk

Been sexually assaulted

Argued with family or friends about their drinking

Had Financial troubles due to some else's drinking

Had family or marriage problems due to someone else's drinking

Been a passenger with a drunk driver

Been in a motor car accident due to some else's drinking

$\mathrm{n} / \mathrm{a}=$ Not available

- = Non-significant relationship

* $=p<.001$ $\mathrm{n} / \mathrm{a}$

$\mathrm{n} / \mathrm{a}$

$11.3(1.5-82.7)$

$\mathrm{n} / \mathrm{a}$

$\mathrm{n} / \mathrm{a}$ 